Proceedings of XIX International Scientific Conference "New Technologies and Achievements in Metallurgy, Material Engineering, Production Engineering and Physics", Częstochowa, Poland, June 7-8, 2018

\title{
Impact of the Effects of Sample Geometry and Forms on the Magnetic Properties of NiFeCuMo Alloy
}

\author{
R. GozDur ${ }^{a, *}$, B. GuzOWski ${ }^{a}$ AND M. HASIAK ${ }^{b}$ \\ ${ }^{a}$ Łódź University of Technology, Department of Semiconductor and Optoelectronics Devices, \\ Wolczanska 211/215, 90-924 Łódź, Poland \\ ${ }^{b}$ Wrocław University of Science and Technology, Department of Mechanics and Materials Science Engineering, \\ M. Smoluchowskiego 25, 50-370 Wrocław, Poland
}

\begin{abstract}
The investigations of magnetic properties were focused on the influence of sample thickness on coercivity and permeability of magnetic substrates made of NiFeCuMo alloy. The transition from $2 \mathrm{~mm}$ thick samples to $200 \mathrm{~nm}$ films samples resulted in a significant increase in coercivity and a reduction in permeability. The deterioration of the magnetic properties of $\mathrm{NiFeCuMo}$ thin layers required 1000 times higher external magnetizing field than the typical coercive field for pre-annealed NiFeCuMo sheets and bulk forms.
\end{abstract}

DOI: 10.12693/APhysPolA.135.308

PACS/topics: 85.80.Fi, 75.70.Ak, 75.60.Ej

\section{Introduction}

Soft magnetic substrates have attracted much attention for the use in modern sensors and spintronic devices [1-3]. One of the soft magnetic materials is ironnickel $\left(\mathrm{Ni}_{80} \mathrm{Fe}_{20}\right.$ wt.\%) alloy, also called permalloy (Py). Very high relative permeability, low coercivity, low magnetic anisotropy, and low costs of Py make it a promising material for spintronic research $[4,5]$. The physical properties of $\mathrm{NiFe}$ alloys are measured in terms of magnons propagation [6], damping factor [7] and magnetic anisotropy [8].

The first observation of spin Seebeck effect (SSE) was made with the use of the $\mathrm{Ni}_{81} \mathrm{Fe}_{19}$ substrate [9] and since then $\mathrm{Ni}$-Fe-based alloys have been investigated to increase inverse spin Hall effect voltage $\left(V_{I S H E}\right)$ or to improve the efficiency of spintronic devices [10-12].

Excellent magnetic properties of permalloy increase the number of $\mathrm{NiFe}$ alloy applications such as: spin valves [13], spin-wave multiplexer [14], spin-wave signal splitter [15] and also in racetrack memory [16]. Nowadays, pure Py alloys and multilayers with Py [17], the Py nanowires [18], filtering or guiding layers [19] are investigated. Different excitation methods of spin waves in Py are developed e.g. by laser pulses [20], thermoelectric modules [10], or microwave antennas [21].

The Py is an electric conductor, therefore observation of spin waves is disturbed by the flow of charge current and it is harder to measure pure spin voltage in Py than in an electric insulator. Nowadays, a separation of the spin Seebeck effect from anomalous and planar Nernst effect is investigated [22-25].

*corresponding author; e-mail: gozdur@p.lodz.pl
The spin waves propagation in a ferromagnetic bulk is described by the Landau-Lifshitz-Gilbert equation $[26,27]$ :

$$
\frac{\partial \boldsymbol{M}}{\partial t}=\gamma \boldsymbol{M} \times \boldsymbol{H}_{e f f}-\frac{\alpha}{M} \boldsymbol{M} \times \frac{\partial \boldsymbol{M}}{\partial t},
$$

where $\boldsymbol{M}$ is a magnetic moment, $\gamma<0$ is the gyromagnetic ratio for an electron spin, $\boldsymbol{H}_{\text {eff }}$ is an effective field, $M$ is the magnitude of $\boldsymbol{M}$ and $\alpha$ is the Gilbert damping coefficient. Magnetic field in the sample is an effective field $\boldsymbol{H}_{\text {eff }}$ and it is a resultant of four magnetic fields as shown below [28]:

$$
\boldsymbol{H}_{e f f}=\boldsymbol{H}_{d}+\boldsymbol{H}_{e x}+\boldsymbol{H}_{a}+\boldsymbol{H}_{b},
$$

where $\boldsymbol{H}_{d}$ is the magnetostatic field, $\boldsymbol{H}_{e x}$ is the exchange field, $\boldsymbol{H}_{a}$ is the anisotropy field and $\boldsymbol{H}_{b}$ is the external applied field. The formula (3) for magnetostatic field $\boldsymbol{H}_{d}[29]$ :

$$
\boldsymbol{H}_{d}=-\nabla \phi, \quad \nabla^{2} \phi=4 \pi \nabla \cdot \boldsymbol{M},
$$

where $\phi$ is scalar potential. $\boldsymbol{H}_{d}$ is related to the Zeeman energy, which is obligatory to unify the direction of all magnetic moments of dipoles when $\boldsymbol{H}_{b}$ is applied. Due to $\boldsymbol{H}_{d}$ the magnetic field inside the sample will be smaller than $\boldsymbol{H}_{b}$. The $\boldsymbol{H}_{e x}$ [29] given below (4) originates from short-range magnetic interactions, which allow the individual magnetic moments to be aligned below the Curie temperatures

$$
\boldsymbol{H}_{e x}=\left(2 A / M_{s}\right) \nabla^{2} \boldsymbol{M},
$$

where $A$ is the exchange constant and $M_{S}$ is the saturation magnetization. Field $\boldsymbol{H}_{a}[30]$ is given by (5):

$$
\boldsymbol{H}_{a}=\frac{2 K}{\mu_{0} M_{s}},
$$

where $K$ is anisotropy constant.

The coercive field $\boldsymbol{H}_{c}$ is related to magnetic properties of the sample such as magnetization, anisotropy, exchange constant and defects of magnetic material [31]. In addition, the mechanical stresses, purity of layers, 
structural defects, anisotropy and eddy currents have influence on the coercivity of magnetic substrate and therefore the value of $\boldsymbol{H}_{\text {eff }}$ is not constant [32]. Moreover, the magnetic properties of magnetic substrates differ with the change of thickness of these substrates [33].

In research papers the spin effect was observed for very different values of external magnetic field for similar samples and systems. For example, in magnetic substrates dedicated to spintronics the spin effects are observed with $\boldsymbol{H}_{b}$ from 50 Oe to 50000 Oe [34, 35]. Therefore, it is not clearly known what the appropriate value of magnetic excitation is.

In this paper the influence of thickness and preparation of the samples on coercivity and hysteresis loops was investigated in different samples made of NiFeCuMo.

\section{Magnetic parameters of permalloy}

By changing the proportion between $\mathrm{Ni}$ and $\mathrm{Fe}$ it is possible to obtain different magnetic properties in permalloy. In alloys with $70-80 \%$ of $\mathrm{Ni}$ the saturation polarization is from 0.7 to $0.8 \mathrm{~T}$ and maximum relative magnetic permeability from 70,000 to 450,000. Permalloy with $55-70 \%$ of Ni exhibits $1.2-1.5 \mathrm{~T}$ saturation polarization and it is often used for tape cores. By reducing the amount of $\mathrm{Ni}$ in permalloy to $35-50 \%$ it is possible to obtain the materials with saturation up to $1.6 \mathrm{~T}$ polarization and relative magnetic permeability from 50,000 to 135,000 [36]. These values can be changed by addition of non-ferromagnetic elements e.g. molybdenum (Mo), copper $(\mathrm{Cu})$ or chromium $(\mathrm{Cr})$. Alloys with addition of Mo have ten times higher permeability and higher resistivity than Py [37]. When cobalt (Co) is added to NiFe the constant permeability and zero hysteresis losses are obtained at low fields of up to $200 \mathrm{~A} / \mathrm{m}$ [5]. NiFeCu alloys are attractive because of their low coercive field [38].

Not only are the typical magnetic parameters investigated. Since the permalloy has been recognized as a promising material for spin caloritronics, also the parameters such as damping constant or gyromagnetic ratio are determined [39]. In addition, different alloys based on $\mathrm{Py}$ are investigated to improve the parameters of spin effects. One of such alloys is NiFeCuMo, which presents softer magnetic properties than pure NiFe [1] and some magnetothermal effects in $\mathrm{NiFeCuMo}$ have been already observed [40]. This alloy has a very low coercive field and therefore the applied value of $\boldsymbol{H}_{b}$ does not have to be high to observe magnons. NiFeCuMo has also low thermal resistance and therefore generation of temperature gradient in such an alloy is more difficult. On the other hand, low thermal resistance enables $\mathrm{NiFeCuMo}$ alloys to be used in spin caloritronics applications since the transport of heat is easier.

\section{Sample preparation and measurement setup}

In the study alloys with nominal composition $\mathrm{Ni}_{77} \mathrm{Fe}_{15} \mathrm{Cu}_{5} \mathrm{Mo}_{3}$ (wt\%) were used in form of sheets, rings and sputtering targets. During the research two types of NiFeCuMo rings $100 \mu \mathrm{m}$ and $2 \mathrm{~mm}$ thick (Fig. 1a

and Fig. 1b), two types of NiFeCuMo sheets $50 \mu \mathrm{m}$ and $100 \mu \mathrm{m}$ thick (Fig. 1c and Fig. 1d), $200 \mathrm{~nm}$ thick NiFeCuMo film sputtered on glass (Fig. 1e) and $8 \mu \mathrm{m}$ thick $\mathrm{NiFeCuMo}$ film sputtered on $\mathrm{Al}_{2} \mathrm{O}_{3}$ substrate (Fig. 1f) were investigated. Samples were numbered from I to VI. $\mathrm{NiFeCuMo} \mathrm{films} \mathrm{were} \mathrm{sputtered} \mathrm{by} \mathrm{thin} \mathrm{film} \mathrm{deposition}$ system Nano 36 from Kurt J-Lesker. The composition (Fig. 2a) was analyzed using an EDS probe X-MAX N80 from Oxford Instruments. The measurements and calculations of percentage weights are collected in Table I. Figure 2b depicts a SEM micrograph of a surface of the sample II.

(a)

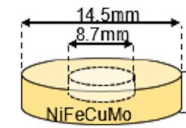

(d)

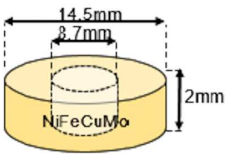

Fig. 1. Investigated NiFeCuMo samples: sample I (a), sample II (b), sample III (c), sample IV (d), sample V (e) and sample VI (f).

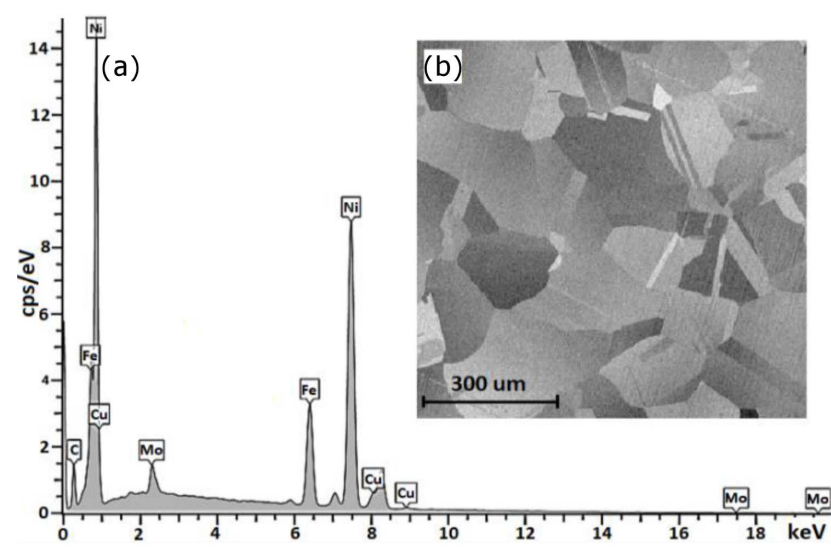

Fig. 2. The EDS spectrum of the sample II micrograph (a), SEM micrograph of the sample II (b).

TABLE I

The nominal and the measured NiFeCuMo composition [wt\%].

\begin{tabular}{c|c|c|c|c|c}
\hline \hline Element & $\mathrm{Ni}$ & $\mathrm{Fe}$ & $\mathrm{Cu}$ & $\mathrm{Mo}$ & $\mathrm{Si}, \mathrm{Mn}$ \\
\hline nominal & 76.6 & 14.7 & 4.5 & 3.3 & $<1.0$ \\
measured & 76.1 & 15.9 & 4.3 & 3.7 & -
\end{tabular}

Magnetic polarization $J$, coercive field $H_{c}$, hysteresis loops $J(H)$ and initial magnetization curves $J(H)$ were measured in order to verify the influence of processing and thickness of samples on magnetic properties. 
The magnetic properties of the samples I and II were measured in accordance with the recommendations of IEC 60404 standards. Magnetic field strength $H$ and polarization $J$ were measured using a shunt resistor and pick-up coils, respectively [41, 42].

The magnetic properties of sputtered $\mathrm{NiFeCuMo} \mathrm{films}$ on $\mathrm{Al}_{2} \mathrm{O}_{3}$ and glass substrates as well as $\mathrm{NiFeCuMo}$ sheet-type sample III and sample IV were recorded at room temperature by VSM magnetometer VersaLab (Quantum Design).

\section{Results and discussion}

The nominal and measured NiFeCuMo samples compositions are shown in Table II. Magnetic properties of the sputtered thin NiFeCuMo films, NiFeCuMo sheets, and reference NiFeCuMo bulk sample were determined based on the static hysteresis loops analysis. In Fig. 3 and Fig. 4 hysteresis loops and coercivity measured for bulk samples were compared. The measurements of these loops were made using method defined in IEC standard (IECM) (sample I and sample II) and VSM magnetometer (sample III and sample IV).

TABLE II

Comparison of $J / J_{\max }$ and $H_{c}$ measurements.

\begin{tabular}{l|c|c|c|c|c}
\hline \hline \multicolumn{1}{c|}{$\begin{array}{c}\text { Type of } \\
\text { sample }\end{array}$} & $\begin{array}{c}\text { Sample } \\
\text { thickness } \\
T[\mu \mathrm{m}]\end{array}$ & \multicolumn{2}{|c|}{$\begin{array}{c}H_{c} \\
{[\mathrm{kA} / \mathrm{m}]}\end{array}$} & \multicolumn{2}{|c}{$\begin{array}{c}J / J_{\max } \\
{[\text { a.u.] }}\end{array}$} \\
\hline $\begin{array}{l}\text { nominal } \\
\text { parameter }\end{array}$ & 1000 & \multicolumn{2}{|c|}{0.015} & \multicolumn{2}{|c}{$0.80 \mathrm{~T}$} \\
\hline $\begin{array}{l}\text { Measurement } \\
\text { method }\end{array}$ & & $\mathrm{VSM}$ & $\mathrm{IECM}$ & $\mathrm{VSM}$ & $\mathrm{IECM}$ \\
\hline sample I & 100 & - & 0.06 & - & 0.99 \\
sample II & 2000 & - & 0.13 & - & 1.00 \\
sample II & 50 & 0.63 & - & 0.98 & - \\
sample IV & 100 & 1.25 & - & 0.99 & - \\
sample V & 0.2 & 2.00 & - & $3.7 \times 10^{-4}$ & - \\
sample VI & 8.0 & 0.27 & - & 0.054 & - \\
& & & &
\end{tabular}

As shown in Fig. 3, relative magnetic polarization $J / J_{\max }$ is similar for all bulk samples. Influence of stray field on sample III and sample IV is observed and therefore they required higher applied $\boldsymbol{H}$ to obtain saturation in comparison to ring-type samples. As shown in Fig. 4, the smallest $\boldsymbol{H}_{c}$ was measured for ring-type samples $\boldsymbol{H}_{c}=0.06 \mathrm{kA} / \mathrm{m}$ (sample I) and $\boldsymbol{H}_{c}=0.13 \mathrm{kA} / \mathrm{m}$ (sample II). For the sheet-type samples the measured coercive fields were higher $\boldsymbol{H}_{c}=0.63 \mathrm{kA} / \mathrm{m}$ (sample III) and $\boldsymbol{H}_{c}=1.25 \mathrm{kA} / \mathrm{m}$ (sample IV), since the defected volume of sample near the processed edges is significant in relation to total volume of sheet-type samples.

Changes in saturation and coercivity for thin film samples $\leq 100 \mu \mathrm{m}$ are shown in Figs. 5 and 6 . The measurements of these loops were made using VSM. The hysteresis loops measured for sheet-type samples and thin film samples are shown in Fig. 5. The saturation scatter level of measured samples is very high while the slope

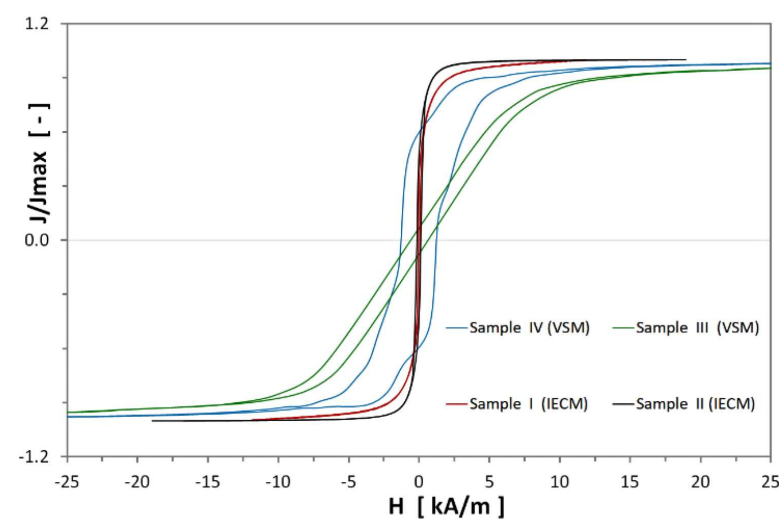

Fig. 3. Comparison of hysteresis loops measured with VSM and IECM methods.

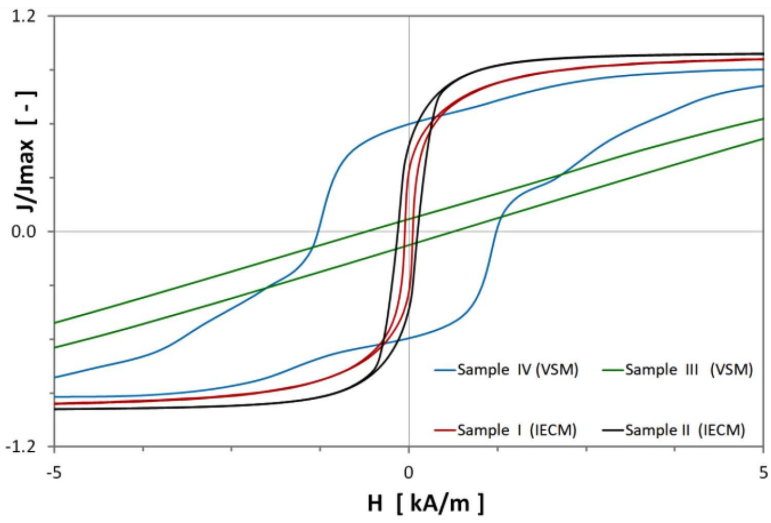

Fig. 4. Comparison of coercivity measured with VSM and IECM methods.

of magnetization is similar. Sample V where NiFeCuMo was sputtered on glass had very poor magnetic properties with $\boldsymbol{H}_{c}=2 \mathrm{kA} / \mathrm{m}$ (Fig. 6) and it cannot be used in spintronics applications.

The comparison presented in Fig. 6 shows that the coercivity field measured for sample VI was $\boldsymbol{H}_{c}=$ $0.27 \mathrm{kA} / \mathrm{m}$ and it was smaller than for sample III $\left(\boldsymbol{H}_{c}=0.63 \mathrm{kA} / \mathrm{m}\right)$ and sample IV $\left(\boldsymbol{H}_{c}=1.25 \mathrm{kA} / \mathrm{m}\right)$.

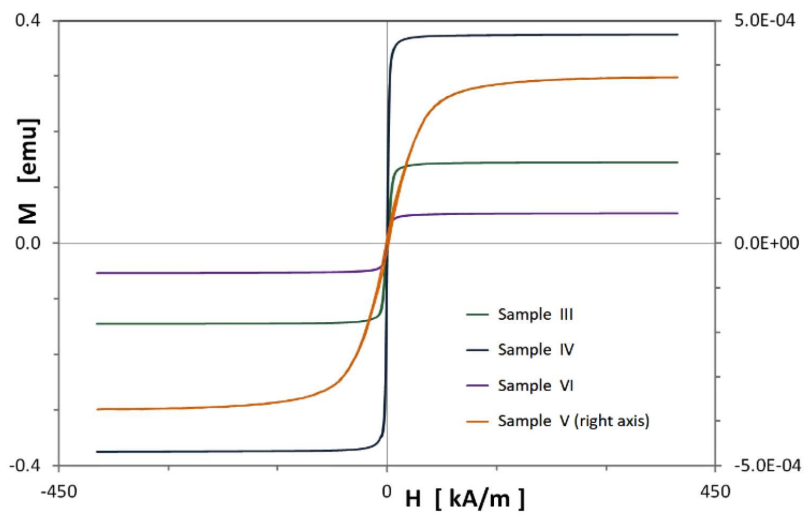

Fig. 5. Hysteresis loops of samples III-VI measured with VSM. 


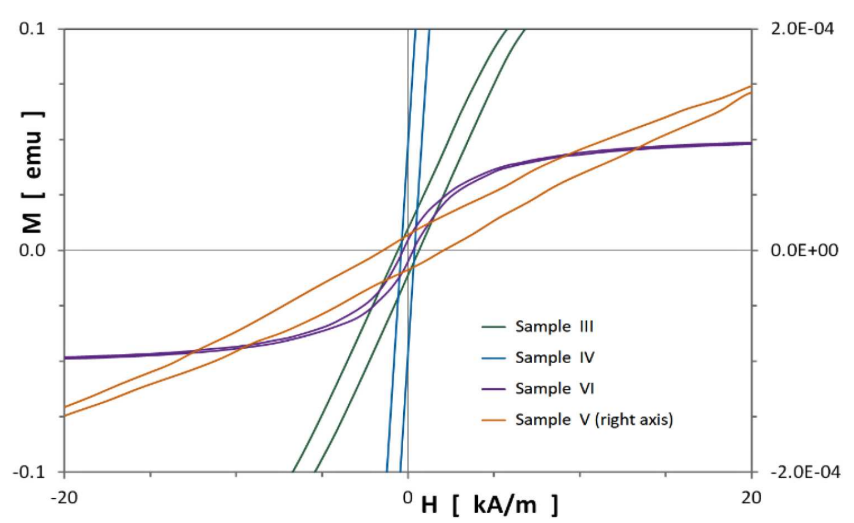

Fig. 6. Coercivity of the investigated samples.

Magnetization of pure glass and ceramic substrates was taken into account and it had magnetic response at the level of $10 \mathrm{ppm}$ in comparison to magnetization of $\mathrm{NiFe}-$ CuMo samples.

The highest convergence of measurements with the nominal parameters was observed for sample I and sample II tested by the IECM. Deterioration of magnetic parameters of bulk samples (Figs. 3 and 4) examined with VSM might be related to the preparation of the test samples, implementation of another measurement method or inhomogeneity of magnetic properties.

\section{Conclusions}

This study shows that the coercivity and hysteresis loops of $\mathrm{Ni}_{77} \mathrm{Fe}_{15} \mathrm{Cu}_{5} \mathrm{Mo}_{3}$ alloy were affected by the sample thickness and its preparation. Smallest coercive fields were measured for the ring-type samples $\boldsymbol{H}_{c}=$ $0.06 \mathrm{kA} / \mathrm{m}$ and $\boldsymbol{H}_{c}=0.13 \mathrm{kA} / \mathrm{m}$ (latter with larger thickness) and they were in good agreement with the nominal parameter. When the alloy was deposited as a film (thickness of $200 \mathrm{~nm}$ ) on a glass substrate, the worst parameters of $\boldsymbol{H}_{c}=2 \mathrm{kA} / \mathrm{m}$ were observed and could be caused by the inhomogeneity of the layer. It has been proved that constant value of $\boldsymbol{H}_{c}$ should not be assumed when studying the magnetic behavior of samples with different thickness and form: discrepancy between rated and measured parameters reached more than $10^{3}$.

\section{References}

[1] J. Choi, D. Hwang, J. Rhee, S. Lee, Thin Solid Films 519, 8394 (2011).

[2] H. Kuru, H. Kockar, M. Alper, J. Magn. Magn. Mater. 444, 132 (2017).

[3] D. Meier, T. Kuschel, L. Shen, A. Gupta, T. Kikkawa, K. Uchida, E. Saitoh, J.-M. Schmalhorst, G. Reiss, Phys. Rev. B 87, 054421 (2013).

[4] D. Oleksakova, P. Kollar, J. Fuzer, M. Kusy, S. Roth, K. Polanski, J. Magn. Magn. Mater. 316, e838 (2007).

[5] D. Jilies, Introduction to Magnetism and Magnetic Materials, Champman and Hall, 1998.
[6] H. Nakayama, K. Ando, K. Harii, T. Yoshino, R. Takahashi, Y. Kajiwara, K. Uchida, Y. Fujikawa, E. Saitoh, Phys. Rev. B 85, 144408 (2012).

[7] T. Manago, K. Yamanoi, S. Kasai, S. Mitani, J. Appl. Phys. 117, 17D121 (2015).

[8] D. Rodrigues, A. Klautau, A. Edstrom, J. Rusz, L. Nordstrom, M. Pereiro, B. Hjorvarsson, O. Eriksson, Phys. Rev. B 97, 224402 (2018).

[9] K. Uchida, S. Takahashi, K. Harii, J. Ieda, W. Koshibae, K. Ando, S. Maekawa, E. Saitoh, $\mathrm{Na}$ ture 455, 778 (2008).

[10] P.B. Jayathilaka, C. Miller, J. Magn. Magn. Mater. 449, 228 (2018).

[11] K.K. Tikuisis, L. Beran, P. Cejpek, K. Uhlirova, J. Hamrle, M. Vanatka, M. Urbanek, M. Veis, Mater. Des. 114, 31 (2017).

[12] Y. Ciao, L. Wang, C. Feng, J. Zhang, F. Yang, S. Li, S. Jiang, Y. Liu, G. Yang, C. Zhao, F. Song, Z. Zhou, G. Yu, Mater. Lett. 137, 351 (2014).

[13] B.D. Tu, L. Cuong, T. Hung, D. Giang, T. Danh, N. Duc, C. Kim, Trans. Magn. 45, 2378 (2009).

[14] K. Vogt, F.Y. Fradin, J.E. Pearson, T. Sebastian, S.D. Bader, B. Hillebrands, A. Hoffmann, H. Schultheiss, Nat. Commun. 5, 3727 (2014).

[15] F. Heussner, A.A. Serga, T. Bracher, B. Hillebrands, P. Pirro, Appl. Phys. Lett. 111, 122401 (2017).

[16] S. Parkin, S. Yang, Nat. Nano. 10, 195 (2015).

[17] M. Xu, G. Luo, C. Chai, Z. Mai, W. Lai, Z. Wu, D. Wang, J. Cryst. Growth 212, 291 (2000).

[18] Y. Gao, B. You, X.Z. Ruan, M.Y. Liu, H.L. Yang, Q.F. Zhan, Z. Li, N. Lei, W.S. Zhao, D.F. Pan, J.G. Wan, J. Wu, H.Q. Tu, J. Wang, W. Zhang, Y.B. Xu, J. Du, Sci. Rep. 6, 1 (2016).

[19] R. Silvani, M. Kostylev, A.O. Adeyeye, G. Gubbiotti, J. Magn. Magn. Mater. 450, 51 (2018).

[20] A. Kamimaki, S. Iihama, Y. Sasaki, Y. Ando, S. Mizukami, Trans. Magn. 53, 4300604 (2017).

[21] V. Demidov, S.O. Demokritov, Appl. Phys. Lett. 91, 252504 (2007).

[22] J. Holanda, O. Alves Santos, R.O. Cunha, J.B.S. Mendes, R.L. Rodríguez-Suárez, A. Azevedo, S.M. Rezende, Phys. Rev. B 95, 214421 (2017).

[23] A.D. Avery, M.R. Pufall, B.L. Zink, Phys. Rev. Lett. 109, 196602 (2012).

[24] M. Schmid, S. Srichandan, D. Meier, T. Kuschel, J.-M. Schmalhorst, M. Vogel, G. Reiss, C. Strunk, C.H. Back Phys. Rev. Lett. 111, 187201 (2013).

[25] H. Kannan, X. Fan, H. Celik, X. Han, J.Q. Xiao, Sci. Rep. 7, 6175 (2017).

[26] E.M. Lifshitz, L.P. Pitaevskii, Statistical Physics, Part 2, 3rd ed., Course of Theoretical Physics, Vol. 9, Pergamon, Oxford 1980.

[27] T.L. Gilbert, Trans. Magn. 40, 3443 (2004).

[28] A. Khitun, M. Bao, K.L. Wang, Trans. Magn. 44, 2141 (2008).

[29] J. Fidler, R.W. Chantrell, T. Schrefl, M.A. Wongsam, Encyclopedia of Materials: Science and Technology, 2nd ed., 2001, p. 5642. 
[30] G. Bertotti, I. Mayergoyz, Hysteresis in Magnetic Materials For Physicists, Materials Scientists, and Engineers, Vol. III, Hysteresis in Materials, Academic Press, 2005.

[31] G. Hadjipanayis, Magnetic Hysteresis in Novel Magnetic Materials, Vol. 1, Springer-Science + Business Media, 1997, p. 737.

[32] D. Jiles, Introduction to Magnetism and Magnetic Materials, 2nd ed., Chapman and Hall, 1998.

[33] A. Kehlberger, U. Ritzmann, D. Hinzke, E. Guo, J. Cramer, G. Jakob, M. Onbasli, D. Kim, C. Ross, M. Jungfleisch, B. Hillebrands, U. Nowak, M. Kläui Phys. Rev. Lett. 115, 096602 (2015).

[34] T. Kikkawa, K. Uchida, Y. Shiomi, Z. Qiu, D. Hou, D. Tian, H. Nakayama, X.-F. Jin, E. Saitoh, Phys. Rev. Lett. 110, 067207 (2013).

[35] T. Seki, K. Uchida, T. Kikkawa, Z. Qiu, E. Saitoh, K. Takanashi, Appl. Phys. Lett. 107, 092401 (2015).

[36] M. Demper, MagNews 24, 1 (2015).
[37] R.D. Enoch, A.D. Fudge, Brit. J. Appl. Phys. 17, 623 (1966).

[38] M. Qader, A. Vishina, L. Yu, C. Garcia, R. Singh, N.D. Rizzo, M. Huang, R. Chamberlin, K.D. Belashchenko, M. Schilfgaarde, N. Newman, J. Magn. Magn. Mater. 442, 45 (2017).

[39] M. Najafi, B. Kruger, S. Bohlens, M. Franchin, H. Fangohr, A. Vanhaverbeke, R. Allenspach, M. Bolte, U. Merkt, D. Pfannkuche, D. Moller, G. Meier, J. Appl. Phys. 105, 113914 (2009).

[40] B. Guzowski, R. Gozdur, M. Lakomski, Acta Phys. Pol. A 133, 541 (2017).

[41] A. Majocha, R. Gozdur, Przeglad Elektrotechniczny 86, 79 (2010) (in Polish).

[42] R. Gozdur, M. Lebioda, L. Bernacki, Acta Phys. Pol. A 128, 98 (2015). 